\title{
Chromatographic Analysis of Petroleum Fractions Used in Oil-Extended Rubber ${ }^{1}$
}

\author{
Dominic J. Termini and Augustus R. Glasgow
}

(October 10, 1961)

\begin{abstract}
The classification of oils with respect to differences in composition is important in their use in the manufacture of oil-extended butadiene-styrene rubber. A rapid chromatographic method of analysis has been developed in which 2.5- to 3.0-gram samples of oil are desorbed from silica gel into five different fractions by successive elution with pentane, benzene, carbon tetrachloride, and ethanol as eluents. Six extender-oils were analyzed by this method. Physical properties of the separated fractions showed marked differences between fractions of the same oil and similarities between corresponding fractions of the different oils. The chromatographic separation of extender-oils into compositionally different fractions provides a method for evaluation of the effect of different components on specific properties of the finished rubber product.
\end{abstract}

\section{Introduction}

High-boiling oils of petroleum origin are used in the preparation of oil-extended rubber. The oils are complex mixtures of hydrocarbons and also contain compounds of nitrogen, sulfur, and oxygen $[1,2,3,4] .{ }^{2}$ The different components in these oils impart certain desirable and undesirable properties to butadienestyrene copolymer. Classification of the composition of these materials is necessary for proper formulation of such rubbers $[5,6]$.

Rostler and associates [7,8] classify these oils according to the solubility of the oil with sulfuric acid of varying concentration into four groups; namely, nitrogen bases, first acidaffins, second acidaffins, and paraffins. Kurtz and associates have published data supporting a classification of these oils based on the relationship between the viscosity-gravity constant and viscosity $[9,10]$, the viscosity-gravity constant and refractivity intercept $[11,12]$, and the density and refractivity intercept [13]. Chromatographic techniques $[14,15,16,17]$ with measurements of the physical properties of the separated fractions have also been used to classify these oils.

The chromatographic method of analysis described in this paper was developed as a rapid method for characterizing these oils. It differs from previous silica-gel adsorption methods for viscous oils $[14,17,18]$ in that the oil is separated into five compositionally different fractions instead of two fractions. Samples of six oils certified for use as rubber-processing oils by the Federal Facilities Corporation were analyzed by this procedure.

\section{Adsorption and Elution}

The adsorption column used was $85 \times 1.5 \mathrm{~cm}$, and was fitted with a reservoir at the top and a $1 \mathrm{~mm}$

1 This work was performed under the sponsorship of the Federal Facilities Corporation, Office of Synthetic Rubber, as part of the Government Synthetie Rubber Program.

2 Figures in brackets indicate the literature references at the end of this paper. capillary $0.5 \mathrm{~cm}$ long at the bottom. It was packed in the usual way with about $90 \mathrm{~g}$ of silica gel (28-200 mesh). Removal of the lower boiling solvents from the eluted oil in each fraction was accomplished by distillation in a stream of nitrogen from a pot heated by a water bath.

In preliminary tests of the effectiveness of removal of the solvent by distillation, it was found that a solution of $100 \mathrm{ml}$ pentane and $3 \mathrm{~g} n$-dotriacontane allowed a substantially complete recovery of the high boiling compound; the amount recovered was the same within 0.02 percent of the amount added.

The eluting agents (pentane, benzene, carbon tetrachloride, and absolute alcohol) were redistilled solvents. Preliminary tests indicated that these agents would remove small amounts of nonvolatile material from the gel. On the basis of $2.5-3.0 \mathrm{~g}$ samples of oils separated, the error introduced by alcohol extraction of the gel amounted to about 0.2 weight percent; with the other eluting agents, the error was about 0.02 weight percent.

\section{Chromatographic Separation}

\subsection{Procedure}

A sample of 2.5 to $3.0 \mathrm{~g}$ of the whole oil was weighed in a $10 \mathrm{ml}$ beaker and transferred to the column by a few washings of $5 \mathrm{ml}$ pentane each. The reservoir was then filled with $250 \mathrm{ml}$ pentane and this solution allowed to drain. This elution was followed successively by $100 \mathrm{ml}$ pentane, $160 \mathrm{ml}$ benzene, $160 \mathrm{ml}$ carbon tetrachloride, and $250 \mathrm{ml}$ ethanol. Each solvent was added just before the last of the preceding liquid entered the adsorbent; the reservoir was not allowed to become completely empty. The collection of a fraction was terminated when the next eluent was about two-thirds down the adsorption section. The visibility of the fronts between the different eluents in the column made it easy to observe the above condition. Before exchanging receivers, the tip of the adsorption column was washed 
with some of the appropriate solvent to redissolve deposited material. After the final fraction had been collected, carbon tetrachloride was used to wash the tip because of the very slight solubility of the last fraction in ethanol. In the separation, the less strongly adsorbed components are eluted first, followed by those more strongly adsorbed. An important function of the carbon tetrachloride, as an eluent preceding ethanol, is to solubilize the ethanol-desorbable constituents which are very slightly soluble in ethanol. By this procedure, the entire sample was recovered. The volatile solvents in the eluted fraction were removed by distillation and the weights of the oil residues were determined.

\subsection{Evaluation of Procedure}

The effectiveness of the chromatographic separation was evaluated from experimeints performed on solutions containing known amounts by weight of "saturates" (paraffins and cycloparaffins) and "aromatics" that were separated from an aromatic type oil (Sundex 53). For this separation, $150 \mathrm{~g}$ of the oil was processed according to the program shown in figure 1. For this large-scale separation, a $70 \mathrm{~mm}$ diam column, packed with $1,750 \mathrm{~g}$ of silica gel (28-200 mesh) was used. Five main fractions (I-P, II-B, III-B, IV-B, and V-M) were eluted from this column with pentane, benzene, and methanol, respectively. Fractions I-P and III-B were rechromatographed in smaller columns. The refractive indices given in figure 1 refer to those of the oil portions. A still further separation of lot II-P was made in order to remove some material having a higher refractive index. The amounts of these fractions in lot II-P, expressed as weight percent, were: II-P1, 96.6; II-P2, 1.5 ; II-P3, 1.0 ; and II-P4, 0.6.

The saturate portion, lot II--P2, used in preparing known solutions A through $\mathrm{H}$ (table 1 ) was investi-

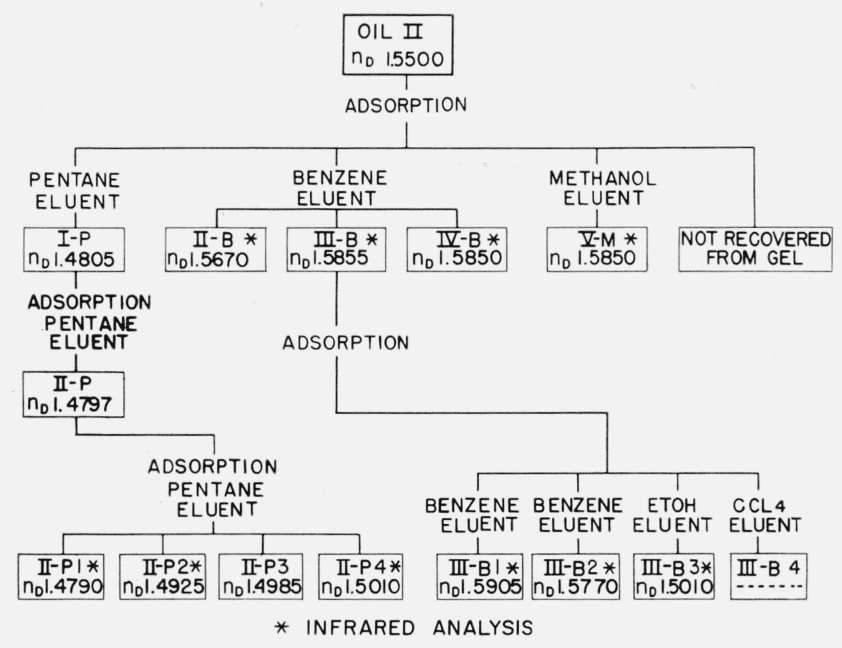

FiguRE 1. Chromatographic separation of $150 \mathrm{~g}$ of a rubberprocessing oil.

II-P, II-P1, III-B and III-B1 are portions used in preparing test solutions of saturates and aromatics for evaluating the analytical chromatographic procedure. $n_{D}=$ refractive index at $25^{\circ} \mathrm{C}$. gated for possible inclusion of some 1-ring aromatic material. The refractive index of this portion was 1.4797 at $25^{\circ} \mathrm{C}$, whereas the refractive index of the eluted portions of the test solution E was 1.4790 . Some of lot II-P was further fractionated by adsorption as shown in figure 1 . The infrared analysis of these fractions showed that benzene ring compounds were present in fraction II-P4 and absent in fraction II-P1. A second series of solutions, I through $\mathrm{K}$ in table 1, was prepared from lot II-P1, which was substantially free of aromatics.

TABLE 1. Chromatographic separations of test solutions of saturates (paraffins and cycloparaffins) and aromatics

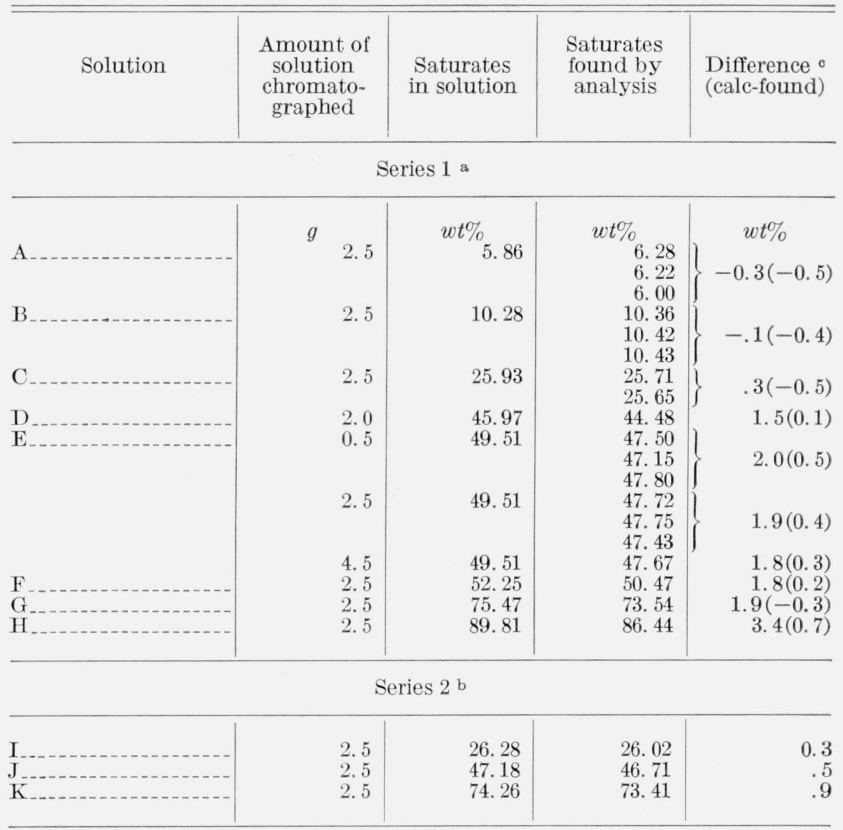

a These solutions were prepared from lots II-P (saturates) and III-B (aromatics). It was later found that this saturate portion contained some aromatics. b These solutions were prepared from lots II-P1 (saturates) and III-B1 (aromaties). This saturate portion was free of aromaties.

- Values in parentheses corrected for about 3 percent aromatics in saturate portion II-P.

A summary of the results of a study of the infrared spectra ${ }^{3}$ of the fractions separated from this oil follows:

1. Lot II-P1: no aromatic rings.

2. Lot II-P2: indication of aromatic ring compounds.

3. Lot II-P4: polynuclear aromatic or single-ring aromatic with long straight chain.

4. Lot III-B1: large aromatic type molecules with few side chains, slight indication of $\mathrm{NH}$ group.

5. Lot III-B2: aromatic pattern about the same as lot III-B1, but indicates more $\mathrm{NH}$ or possibly $\mathrm{OH}$; possible presence of carbonyls which were not present in lot III-B1. The combination of $\mathrm{NH}, \mathrm{OH}$, and carbonyl would indicate the presence of carboxylic acid or acid amide.

3 The infrared analyses were performed by J. E. Stewart, formerly of the Gas Chemistry Section, Chemistry Division. 
6. Lot III-B3: greatest number of aromatic rings, different from lots III-B1 and III-B2; possible presence of a sulfoxide or a sulfone.

7. Lots II-B, III-B, and IV-B: largely aromatic; no indication of oxygen, sulfur, or nitrogen compounds.

8. Lot V-M: resembles lot III-B2.

Experiments were performed to determine the relation between the volume of eluent and the amount of oil desorbed. In the first of these experiments about $0.7 \mathrm{~g}$ of saturated hydrocarbons (lot $\mathrm{P}-1$, fig. 1) was adsorbed on $90 \mathrm{~g}$ of silica gel in the small column and eluted with pentane. A series of $20 \mathrm{ml}$ fractions were collected and the weight of oil in each determined. These results are shown in figure 2 . The bulk of the oil was recovered in the first two fractions; the amount recovered in each of the succeeding fractions is shown on an expanded scale.

Similar experiments were performed in which $0.84 \mathrm{~g}$ of aromatic hydrocarbons (lot III-B, fig. 3) were adsorbed and then eluted with pentane and benzene. The results are shown in figure 3 . The amounts of material recovered in successive $20-\mathrm{ml}$ fractions of the pentane eluent are shown on an expanded weight scale. It will be noted that only $0.012 \mathrm{~g}$ was eluted by pentane; the remainder was rapidly eluted by benzene, the bulk appearing in the first $20 \mathrm{ml}$.

In a third experiment, a solution containing both saturates and aromatics was adsorbed and eluted, first with pentane, followed by benzene; the results are shown in figure 4 . The original solution was prepared from $0.2875 \mathrm{~g}$ of fraction $\mathrm{I}-\mathrm{P}$ (saturates) and $0.9845 \mathrm{~g}$ of fraction III-B (aromatics). These experiments established the volumes of pentane and benzene required to separate a saturate portion and an aromatic portion.

Experiments were also performed to establish the reliability of the method for the determination of saturates (paraffins and cycloparaffins) in an extender-oil. Binary solutions of saturates and aro-

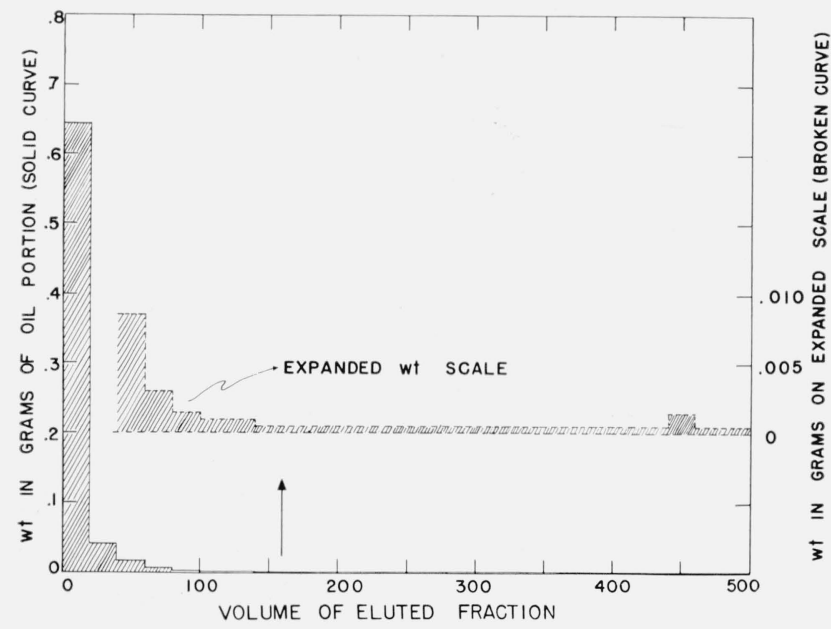

Figure 2. Weight of oil eluted with pentane from test solution of saturates.

Source of saturates; lot II-P, figure 1.

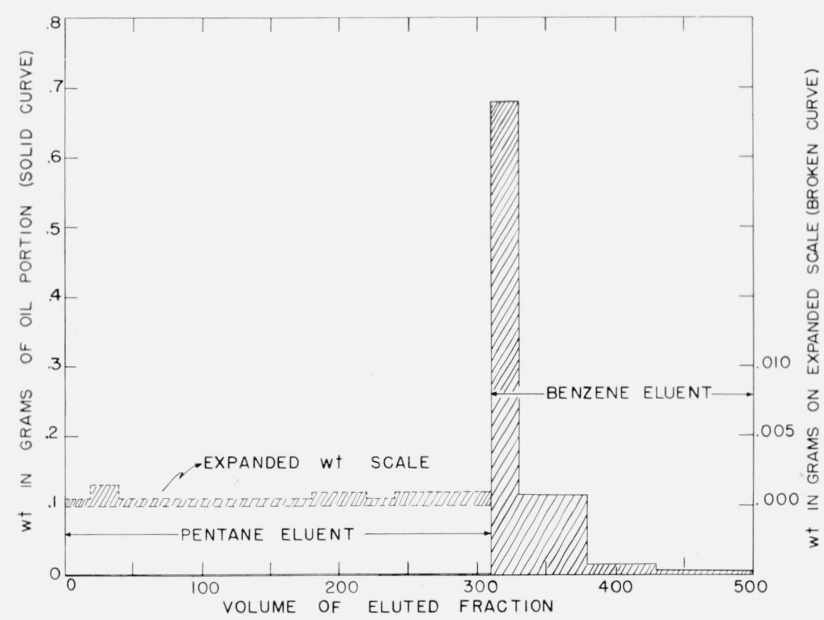

Figure 3. Weight of oil eluted with pentane and benzene from test solution of aromatics.

Source of aromatics; lot III-B, figure 1.

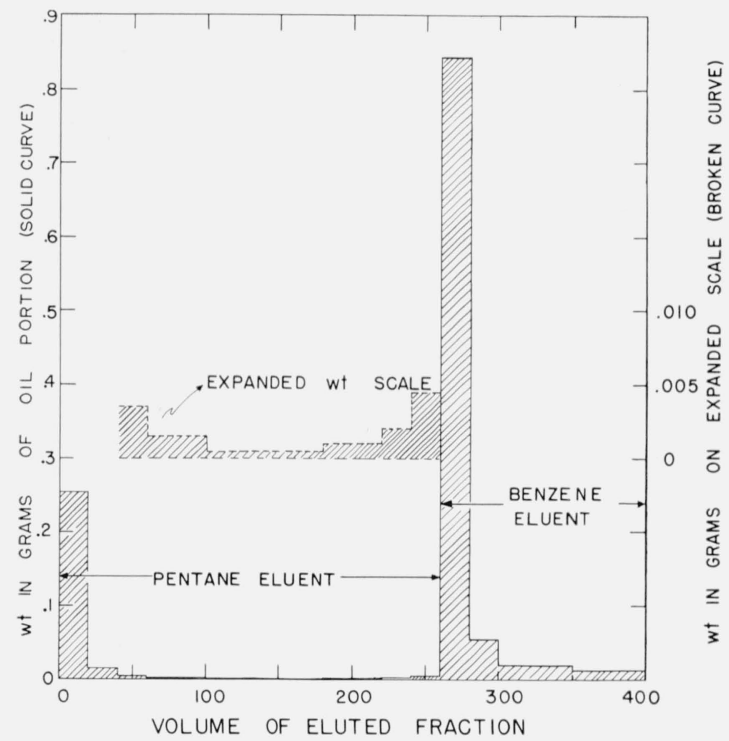

FIGURE 4. Weight of oil eluted with pentane and benzene from test solution of saturates and aromatics.

Source of saturates; lot II-P, figure 1. Source of aromatics; lot III-B, figure 1 .

matics were prepared from fractions II-P and III-B for series 1 and from fractions II-P1 and III-B1 for series 2. These solutions were chromatographed and the results are given in table 1.

The large differences found for solutions of 50 to 90 percent saturates (solutions $\mathrm{D}-\mathrm{H}$ ) can be explained by the presence of a small amount of aromatic-type material in lot II-P. One-ring aromatic compounds containing paraffin side chains are adsorbed on silica gel only slightly more strongly than three- or four-ring cycloparaffins containing paraffin side chains. In solutions $\mathrm{D}$ through $\mathrm{H}$, such aromatic compounds would be retained on the silica gel; but in solutions (A through C) having a lower content of saturated hydrocarbons, they 
TABLE 2. Results of the chromatographic separations of six extender-oils

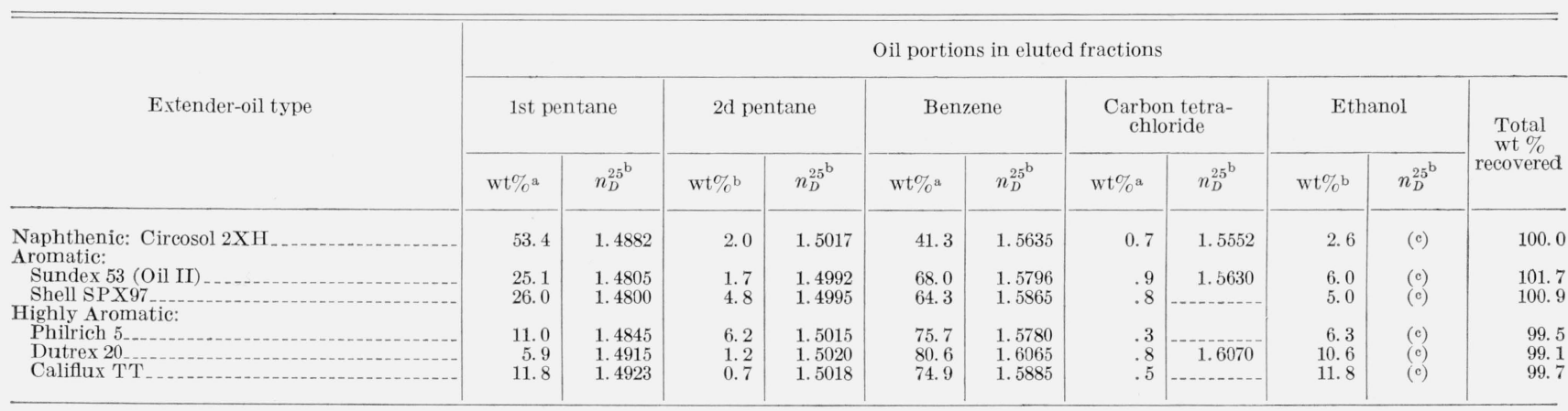

a Expressed in terms of weight of sample of oil chromatographed.

b Refractive index of components from oil in eluted fractions.

c Refractive index not determined because these fractions were highly colored liquids which contained dispersed solids.

would be eluted. When lot II-P1, which had been further fractionated to remove aromatics, was used for the saturate portion these large differences did not appear (solutions I through $\mathrm{K}$ ). When the compositions of solutions A through H are corrected for the 3 percent of aromatics found to be present in lot II-P, much better agreement results (see last column of table 1).

Analyses given in table 1 show that oils containing about 5 to 75 percent saturated hydrocarbons may be analyzed by this procedure with an uncertainty of less than one percent. This range of composition embraces all oils now being used in the manufacture of oil-extended rubbers of the butadiene-styrene types.

\subsection{Analysis of Extender Oils}

A summary of the weight percent and refractive index of the five fractions separated chromatographically from each of the six extender-oils is given in table 2. The infrared absorption spectra of these fractions [19] showed that there were marked differences between fractions separated from the same oil and marked similarities between corresponding fractions separated from the different oils. The spectra have been compared with those [20] for fractions separated from asphalts [21] and by acid extraction of an extender-oil [22]. A more complete study of the composition of the extender oils will be given in another report [1].

\section{Conclusions}

The chromatographic procedure described in this report provides a simple, reproducible, and relatively rapid method of analyzing rubber-processing oils. The selective solvents, pentane, benzene, carbon tetrachloride, and ethanol, separate the oil adsorbed on silica gel into five compositionally different fractions. The analyses provide a means for evaluation of the oils as rubber extenders.

(Page 66A2-152)

\section{References}

[1] A. R. Glasgow and D. J. Termini, Chemical constitution of petroleum fractions used in oil-extended rubber, to be published in J. Research NBS.

[2] F. D. Rossini, B. J. Mair, and A. J. Streiff, Hydrocarbons from Petroleum (Reinhold Publishing Corp., New York, 1953)

[3] K. Van Nes and H. A. Van Weston, Aspects of the constitution of mineral oils (Elsevier Publishing Co., Inc., New York, 1951).

[4] A. N. Sachanen, The chemical consitutents of petroleum (Reinhold Publishing Corp., New York, 1945).

[5] W. K. Taft, J. Duke, A. D. Snyder, M. Feldon, and R. W. Laundrie, Ind. Eng. Chem. 45, 1043 (1953).

[6] K. V. Weinstock, E. B. Storey, and J. S. Sweely, Ind. Eng. Chem. 45, 1035 (1953)

[7] F. S. Rostler and R. M. White, Rubber Age $\mathbf{8 0}, 735$ (1952).

[8] F. S. Rostler and H. W. Sternberg, Ind. Eng. Chem. 41, $598(1949)$.

[9] Sun Oil Company, Marcus Hook, Pennsylvania, A method of classifying oils in oil-extended rubbers, 1954 .

[10] S. S. Kurtz, Jr., R. W. King, W. J. Stout, D. G. Partikian, and E. A. Skrabek, Anal. Chem. 28, 1928 (1956).

[11] S. S. Kurtz, Jr., R. W. King, and J. S. Sweely, Ind. Eng. Chem. 48, 2232 (1956).

[12] Sun Oil Company, Marcus Hook, Pennsylvania, A graphical method of selecting oils used in compounding and extending butadiene-styrene rubbers, 1958.

[13] S. S. Kurtz, Jr., R. W. King, W. J. Stout, and M. E. Peterkin, Anal. Chem. 30, 1224 (1958).

[14] S. S. Kurtz, Jr., and C. C. Martin, India Rubber World 126, 495 (1952).

[15] W. L. Dunkel, F. P. Ford, and J. N. McAteer, Ind. Eng. Chem. 46, 578 (1954).

[16] T. F. Mika, F. M. McMillan, and S. H. Page (Shell Development Company, Emeryville, Calif.), Chromatographic separation of rubber-processing oils from Petroleum sources, presented at 63rd meeting of the Division of Rubber Chemistry, Am. Chem. Soc. (May 27, 1953)

[17] W. J. Stout, R. W. King, M. E. Peterkin, and S. S. Kurtz, Jr., Symposium on Composition of Petroleum Oils, Adsorption and physical property methods, Spe. Tech. Pub. No. 224, Am. Soc. for Testing Materials (1958)

[18] M. R. Lipkin, W. A. Hoffecker, C. C. Martin, and R. E. Ledley, Anal. Chem. 20, 130 (1948).

[19] F. J. Linnig and J. E. Stewart, J. Research NBS 59, 27 (1957) RP2771.

[20] J. E. Stewart, J. Research NBS 58, 265 (1957) RP2759.

[21] L. R. Kleinschmidt, J. Research NBS 54, 163 (1955) RP2577.

[22] F. S. Rostler and R. M. White, Ind. Eng. Chem. 46, 610 (1954). 